\title{
Comparison of Salinity Dependent Mechanical Behaviours of Geopolymer and OPC: An Application to CCS and Oil / Gas Wells
}

\author{
B. Balinee, P. Disaanth and M. C. M. Nasvi
}

\begin{abstract}
Global warming is a severe issue in which the emission of greenhouse gases, especially carbon dioxide $\left(\mathrm{CO}_{2}\right)$, plays a vital role. Methods that are proposed to mitigate $\mathrm{CO}_{2}$ emissions include improving the energy conversion efficiency of fossil fuels, shifting energy production to low carbon sources, enhancing $\mathrm{CO}_{2}$ uptake by terrestrial and marine biomass and capturing $\mathrm{CO}_{2}$ and storing it deep underground. Of all the methods, carbon capture and storage (CCS) deep underground is the best way to reduce atmospheric greenhouse gases which is often responsible for global warming. One of the major issues faced when storing $\mathrm{CO}_{2}$ in depleted oil or gas reservoirs is its leakage through the injection wells. Ordinary Portland Cement (OPC) based well-cement has been used in these oil and gas wells. OPC, however, has issues such as cement degradation, leakage, strength reduction, and durability reduction when used in down-hole environments. Geopolymer can be a good alternative to OPC because of its excellent acid resistance characteristics, high strength and low shrinkage. In a typical wellbore, wellcement will be exposed to saline water that can have different salinity levels. Hence, the main aim of this study was to compare the mechanical behaviours of OPC and geopolymer cement cured in saline water for 7, 28 and 45 days at different salinity levels $(0 \%, 10 \%, 20 \%, 30 \%$ and $40 \%$ of $\mathrm{NaCl})$. A series of experiments were conducted to compare the compressive strength and Young's modulus of OPC and geopolymer. It was observed that the compressive strength of OPC based well-cement increases as the salinity level of the brine water is increased up to $10 \% \mathrm{NaCl}$ and that it thereafter decreases as the $\mathrm{NaCl}$ percentage is further increased. On the other hand, the compressive strength of geopolymer well-cement generally increases as the brine concentration is increased. Based on the findings of this research, it can be concluded that geopolymer as a well-cement can perform better in saline water than OPC based well-cement, and that therefore geopolymer is suitable as a primary well-cement material.
\end{abstract}

Keywords: Brine; carbon dioxide; geopolymer; OPC; well-cement

\section{Introduction}

All over the world, anthropogenic emissions of greenhouse gases have been a major concern with carbon dioxide $\left(\mathrm{CO}_{2}\right)$ playing a major role in these greenhouse gas emissions [1]. Hence, it is essential to reduce carbon dioxide emissions if global warming is to be effectively reduced. Methods such as improving energy conversion efficiency of fossil fuels, shifting energy production to low carbon sources, enhancing $\mathrm{CO}_{2}$ uptake by terrestrial and marine biomass and capturing and storing $\mathrm{CO}_{2}$ deep underground have been suggested to reduce greenhouse gas emissions [2,3]. Of all these solutions, carbon capture and storage (CCS) deep underground which is durable in the long term, safe and of low cost is found to be effective in reducing $\mathrm{CO}_{2}$ emissions $[4,5]$. Sri Lanka is a developing country where there is an increasing demand for electricity, and the country is now focusing on shifting from hydro-electricity to electricity produced from fossil fuels such as coal. There is a coal power plant in Norochcholai, Puttalam, which has been in operation since 2011, and meeting about $50 \%$ of the daily electricity demand of the country. Combustion of coal produces large amounts of $\mathrm{CO} 2$ and hence CCS projects will be useful to Sri Lanka with more and more coal power plants being established in the country. In a CCS project, it is important to ensure cement integrity under various down-hole conditions. Well integrity and zonal isolation depend on many factors. Well-cement is used

Miss. B. Balinee, B.Sc. Eng. (Hons.) (Peradeniya), Department of Civil Engineering, University of Peradeniya. Email: balineebalachandran@gmail.com.

Mr. P. Disaanth, B.Sc. Eng. (Hons.) (Peradeniya), Department of Civil Engineering, University of Peradeniya. Email: disaanth1993@gmail.com.

Eng. (Dr.) M. C. M. Nasvi, B.Sc. (Hons.) (Peradeniya), Ph.D. (Monash), AMIE (Sri Lanka), Senior Lecturer of Civil Engineering, Department of Civil Engineering, University of Peradeniya.

Email:nasvimom@eng.pdn.ac.lk. 
to provide the required well-bore integrity and zonal isolation between different zones. Well-cement has to be carefully designed to meet various demanding requirements such as predictable setting times, high sulphate resistance, high durability, fluid loss control, consistency, low viscosity, low free fluid, and strength $[3,6]$. In a CO2 rich environment, Portland cement will be unstable and will have reduced strength, cement degradation, and increased permeability and will be subjected to chemical attacks [7]. On the other hand, researchers $[1,3,8]$ have found that geopolymer possesses excellent acid resistant characteristics, high strength and low shrinkage compared to OPC. Geoploymer is an aluminasilicate cementitious material, which can be synthesized by mixing the source material (fly ash, metakaolin, slag etc.) with a strong alkaline solution (a combination of $\mathrm{NaOH}$ and $\mathrm{Na} 2 \mathrm{SiO} 3)[1,9,10]$. Hence in the current study, geopolymer was used as the well-cement. The temperature of the Earth increases with depth at a geothermal gradient of $30^{\circ} \mathrm{C} / \mathrm{km}$ and the pore pressure will increase at $10 \mathrm{MPa} / \mathrm{km}$ [2]. The salinity of groundwater which depends on the location can vary from $0 \%$ to $40 \% \mathrm{NaCl}$ $[3,7]$. Hence, it is essential to study the effect of salinity on the mechanical behaviour of wellcement.

Nasvi et al. [3] conducted a research to study the mechanical behaviour of geopolymer saturated in two brine solutions having $\mathrm{NaCl}$ concentrations of $5 \%$ and $15 \%$. They have observed that the strength of geopolymer reduces with the curing period and that the rate of reduction of strength reduces as the brine concentration is increased with the high salt content in the brine solution offering resistance to alkali leaching. Gowthaman et al. [11] studied the mechanical behaviour of Class $\mathrm{G}$ cement for different curing periods $(7,14,28$ and 45 days) at different salinity levels $(0 \%, 10 \%, 20 \%$ and 30 $\%$ ) and at an average temperature of $50{ }^{\circ} \mathrm{C}$. They have concluded that the retardation of hydration causes the strength of Class $\mathrm{G}$ cement to reduce as the salinity level is increased and that the hydration process will cause the strength to increase with the curing period. However, to date, there have been no studies focusing on the comparison of the mechanical behaviours of OPC and geopolymer. Therefore, the aim of this research was to study the effect of salinity on the mechanical behaviour of geopolymer cement and compare it with the mechanical behaviour of typical OPC based well-cement. Uniaxial
Compressive Strength (UCS) test and Scanning Electron Microscopy (SEM) analysis were conducted on both OPC and geopolymer samples to trace the microstructural changes that take place when OPC and geopolymer are cured in brine water.

\section{Experimental Methodology}

Well-cement samples were prepared by using sulphate resisting Ordinary Portland Cement (OPC) and fly ash. Both types of raw material were purchased from INSEE Cement. The chemical compositions of fly ash, Class G cement and sulphate resisting cement are given in Table 1. American Petroleum Industry (API) Class G cement is widely used for constructing wells as it offers a high resistance to sulphate attacks and because it can be used at deeper depths under higher pressure/ temperature conditions. In this research, however, high sulphate resistant OPC based well-cement was used instead of Class G cement since the composition of sulphate resistant cement is similar to that of API Class G cement.

Table 1- Chemical composition of fly ash, API Class $\mathrm{G}$ cement and sulphate resistant cement

\begin{tabular}{|c|c|c|c|}
\hline $\begin{array}{c}\text { Chemical } \\
\text { component }\end{array}$ & $\begin{array}{c}\text { Fly ash } \\
\text { (\%) }\end{array}$ & $\begin{array}{c}\text { API Class } \\
\text { G cement } \\
\text { (\%) [11] }\end{array}$ & $\begin{array}{c}\text { Sulphate } \\
\text { resistant } \\
\text { cement (\%) } \\
\text { [11] }\end{array}$ \\
\hline $\mathrm{SiO}_{2}$ & 52.03 & 22.91 & 20.38 \\
\hline $\mathrm{Al}_{2} \mathrm{O}_{3}$ & 32.31 & 3.89 & 4.79 \\
\hline $\mathrm{Fe}_{2} \mathrm{O}_{3}$ & 7.04 & 4.75 & 3.26 \\
\hline $\mathrm{CaO}$ & 5.55 & 64.7 & 64.40 \\
\hline $\mathrm{MgO}$ & 1.30 & 1.8 & 1.80 \\
\hline $\mathrm{SO}_{3}$ & 0.07 & 0.74 & 2.21 \\
\hline $\mathrm{K}_{2} \mathrm{O}$ & 0.68 & 0.64 & 0.04 \\
\hline $\mathrm{Na}_{2} \mathrm{O}$ & 1.00 & 0.1 & \\
\hline
\end{tabular}

Geopolymer samples were prepared by adding alkaline liquid (AL) to fly ash (FA) at a ratio (AL/FA) of 0.6. A combination of $\mathrm{Na}_{2} \mathrm{SiO}_{3}$ and $\mathrm{NaOH}$ was used as the alkaline liquid at a $\mathrm{Na}_{2} \mathrm{SiO}_{3}: \mathrm{NaOH}$ ratio of 2.5. High sulphate resistant cement paste was prepared with a water: cement ratio of 0.44 (API recommended practice $10 \mathrm{~B}$, for Class $\mathrm{G}$ ) as it has been found 
that this particular water cement ratio gives a higher strength [8]. Paste was cast as shown in Figure 1 in a PVC mould cylindrical in shape which was $38 \mathrm{~mm}$ in diameter and $76 \mathrm{~mm}$ in height. Samples were then oven cured at 50 ${ }^{\circ} \mathrm{C}$ for 24 hours. The temperature of $50{ }^{\circ} \mathrm{C}$ was selected as this is the temperature at the depth of $800-1000 \mathrm{~m}$ at which $\mathrm{CO}_{2}$ sequestration is typically done [12].

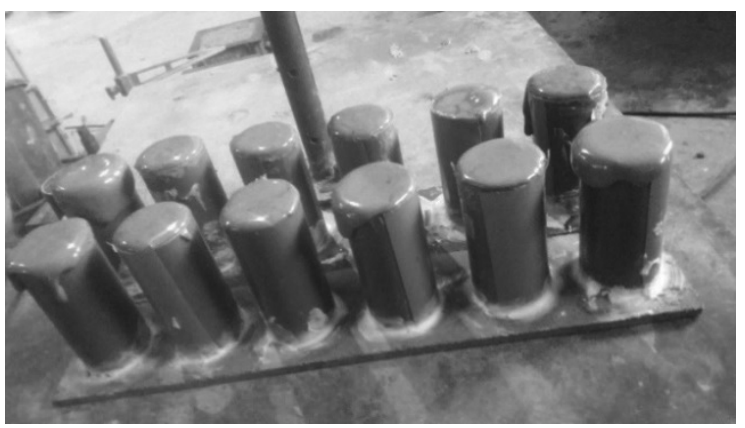

Figure 1 - Geopolymer samples cast in PVC samples

During oven curing, the top surfaces of the samples were covered by polythene to prevent moisture loss. It should be noted that the samples were heat cured only for a period of 24 hours after which they were cured at room temperature. It has been found that geopolymerization occurs almost fully after 24 hours with the reactions getting accelerated by heating and that geopolymer will not develop any further strength with time when cured at elevated temperatures [12]. Therefore, prolonged heat curing will not help geopolymer to gain strength. To ensure uniform test conditions, OPC samples were also heat cured only for a period of 24 hours. After 24 hours of oven curing, the samples were transferred to containers having different brine concentrations (0\%, $10 \%, 20$ $\%, 30 \%$ and $40 \%)$. These brine solutions were prepared by mixing $\mathrm{NaCl}$ salt with distilled water in mix proportions (by weight of water). Samples were cured in brine for 7, 28 and 45 days. To ensure reproducibility, three samples were tested under each condition. At the end of the curing period, Uniaxial Compressive Strength (UCS) test was done on the samples at a stress control loading rate of $0.2 \mathrm{MPa} / \mathrm{sec}$.

\section{Results and Discussion}

\subsection{Comparison of UCS and Young's Modulus of Geopolymer and OPC cured in Saline Water}

The variation of the compressive strength of geopolymer and OPC after curing for 7, 28 and 45 days in water that had different salinity levels are shown in Figures 2 and 3 respectively. The comparison of the compressive strengths of geopolymer and OPC after 7, 28 and 45 days of curing in brine are shown in Figures 4, 5 and 6 respectively. According to Figure 2, the compressive strength of geopolymer generally reduces with the curing period as alkali leaching is initiated with curing. However, the rate of reduction of strength lowers as the salinity level is increased as higher the $\mathrm{NaCl}$ content will give more resistance to leaching [3]. For a given curing period, the strength increases with salinity level (Figures 2 and 4-6) for reasons explained below. There is a significant leaching of alkalis from geopolymer during its curing in normal water, whereas during its curing in brine water there will be an enhanced reaction and lower rate of leaching. Saline water contains significant amounts of $\mathrm{Na}^{+}$and thus $\mathrm{Na}^{+}$and $\mathrm{Ca}^{2+}$ in geopolymer are less prone to leaching. This excess amount of $\mathrm{Na}^{+}$present in geopolymer actually helps to promote reaction rates which provide it with a higher strength $[3,12]$. The rate of increase in the compressive strength for 7, 28 and 45 days are $5 \%, 9 \%$ and $19 \%$ respectively. According to Figure 3, the compressive strength of OPC increases with curing period due to hydration process. During the hydration process, tobomorite gel is formed around the cement grains of OPC. The initial envelope of hydrates acts as a semi-impermeable membrane through which water from the background solution is drawn in due to osmotic pressure. As the pressure builds up, the spines grow and occupy the structure around the cement grains increasing the compressive strength of OPC.

At a particularcuring period, the strength initially increases with salinity level up to $10 \% \mathrm{NaCl}$. The water movement across the membrane will be faster in saline water, causing a rapid increase in the formation of spines which increases the compressive strength as the salinity level is increased up to $10 \% \mathrm{NaCl}$ (Figure 3 and Figures 4-6). Thereafter, the strength starts to decrease with the salinity level (i.e., beyond $10 \% \mathrm{NaCl}$ ) as the high salt content present retards the hydration process. $\mathrm{NaCl}$ dispersed in $\mathrm{C}-\mathrm{S}-\mathrm{H}$ and $\mathrm{Ca}(\mathrm{OH})_{2}$ 
in the form of a solid solution or micro-crystallite precipitation lowers the activation energy required for the decomposition of $\mathrm{Ca}(\mathrm{OH})_{2}$ and causes the retardation of the hydration process [13]. The rate of increase of the strength for OPC up to a $\mathrm{NaCl}$ concentration of $10 \%$ is 2 $11 \%$ depending on the curing time, while the strength reduction rate from $10 \% \mathrm{NaCl}$ to 40 $\% \mathrm{NaCl}$ will vary from $1 \%$ to $22 \%$ depending on the curing time. A typical well-cement has to have a compressive strength of 20 to $50 \mathrm{MPa}$ depending on the depth, to provide thermal isolation and avoid mechanical fracturing $[8,14]$. Thus, geopolymer can replace OPC based well-cement as the strength of geopolymer will be within the recommended values when cured in saline water. Avoiding OPC as wellcement will benefit in two ways: (1) reduction of anthropogenic emissions of greenhouse gases and (2) use of by product materials, such as fly ash, which avoids the high costs associated with landfilling.

Although geopolymer loses its strength with aging, it gains strength with salinity level. The mechanical behaviour of geopolymer is better than that of OPC when cured in saline water, and thus it is suitable for use as well-cement. The average of the stress - strain behaviour of the samples was obtained from the UCS test and the Young's modulus values were calculated from these average stress-strain curves. The variation of Young's modulus of geopolymer and OPC after 28 and 45 days of curing in brine are shown in Figures 7 and 8 respectively. It can be seen from these figures that for a curing period of 28 days, the Young's modulus of geopolymer increases as the salinity level is increased up to $10 \% \mathrm{NaCl}$ and that it starts to decrease thereafter. The rate of increase is $21 \%$ while the rate of decrease beyond $10 \% \mathrm{NaCl}$ is $17 \%$.

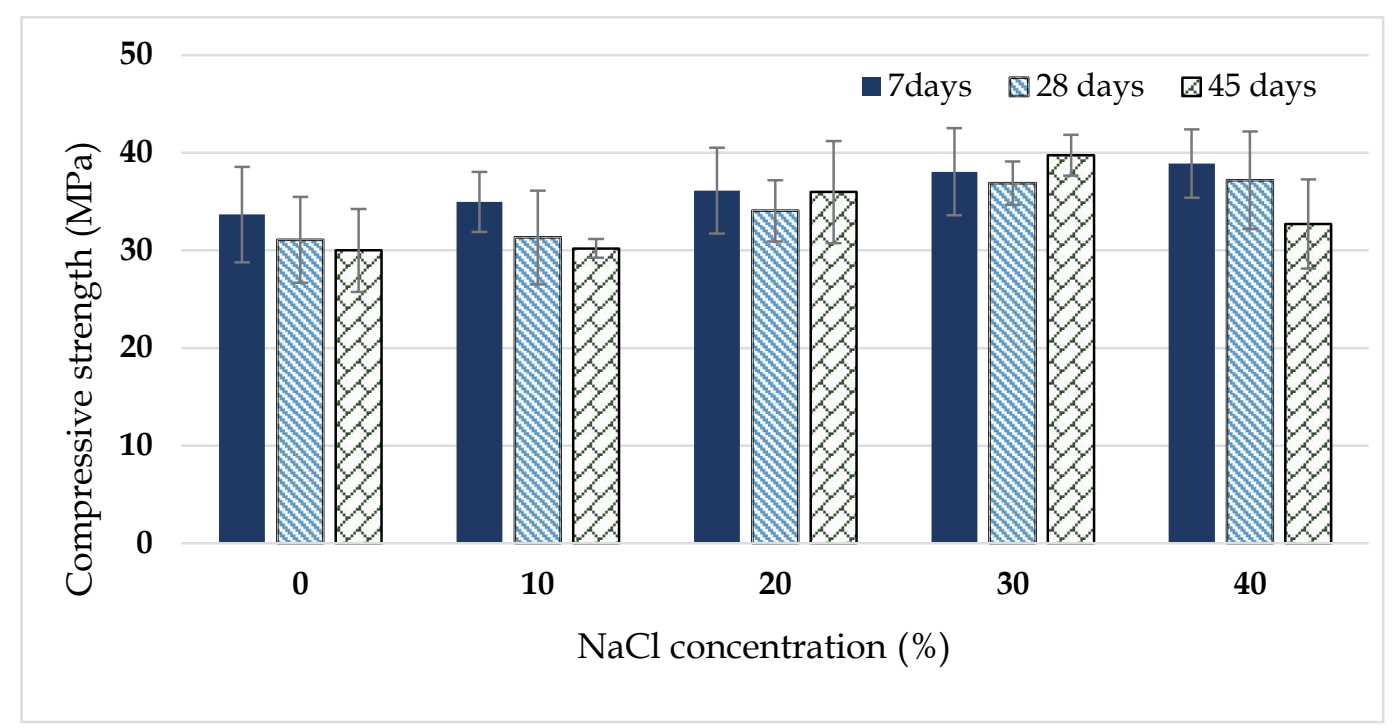

Figure 2 - Variation of the compressive strength of geopolymer with salinity level

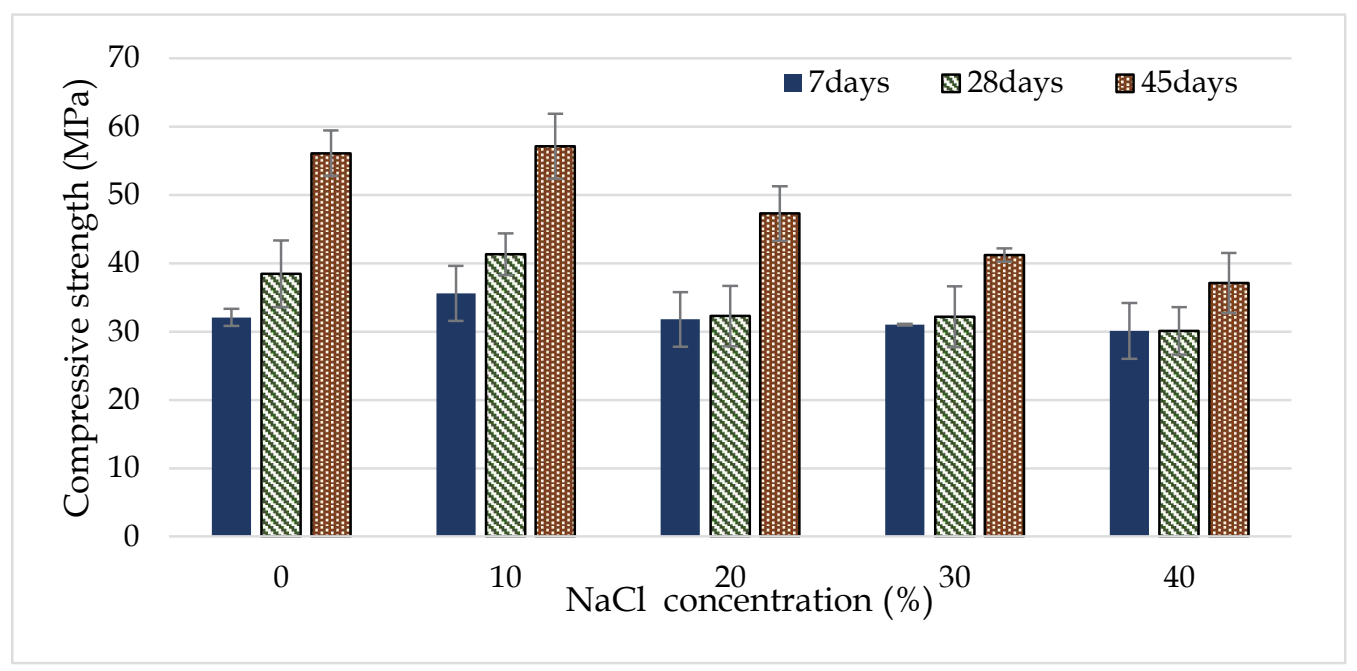

Figure 3 - Variation of the compressive strength of OPC with salinity level 


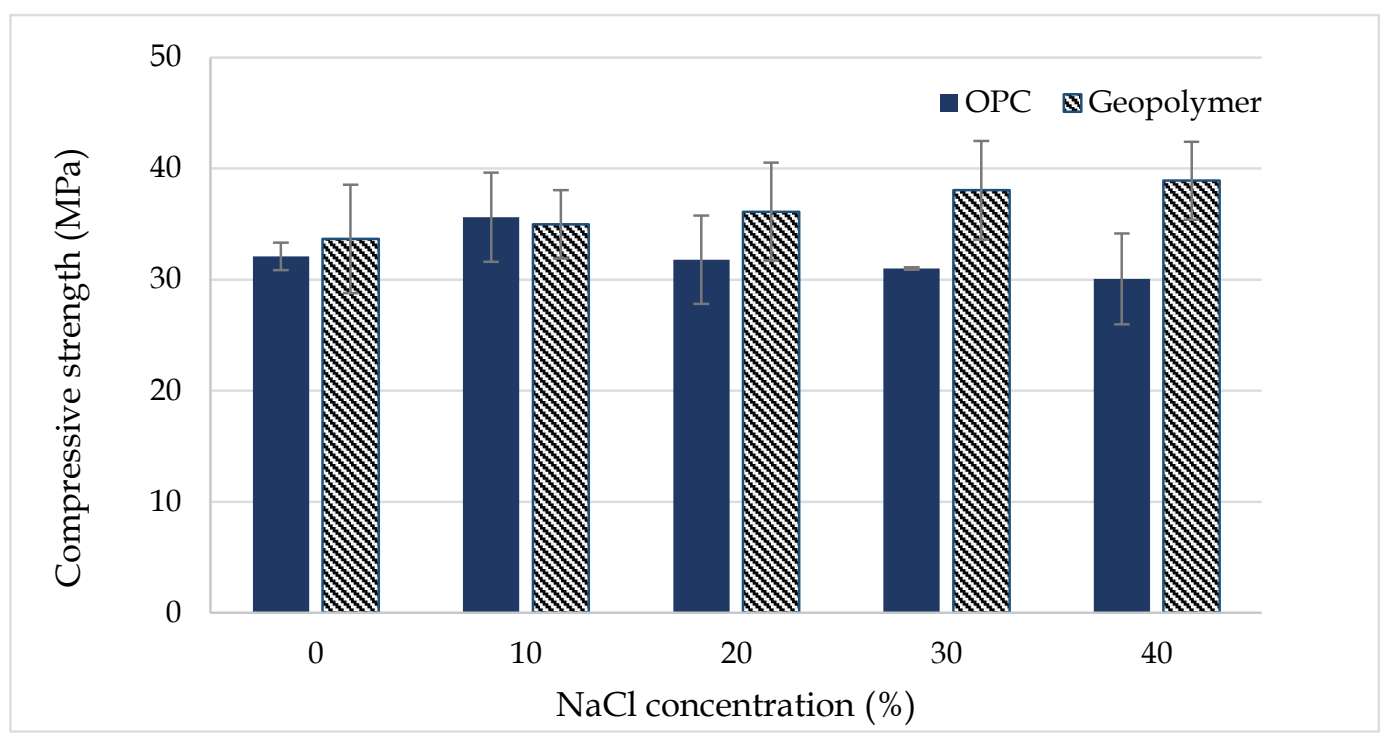

Figure 4 - Comparison of the compressive strengths of OPC and geopolymer with salinity level after 7 days of curing

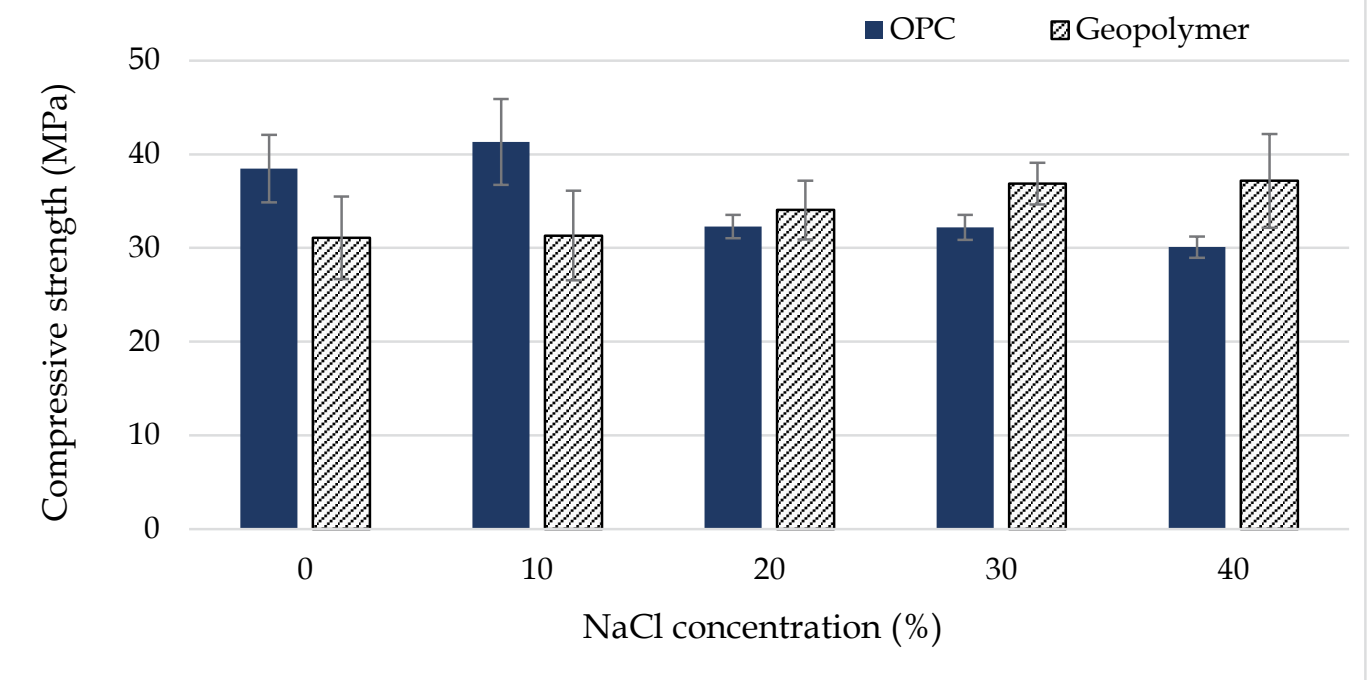

Figure 5 - Comparison of the compressive strength of OPC and geopolymer with salinity level after 28 days of curing

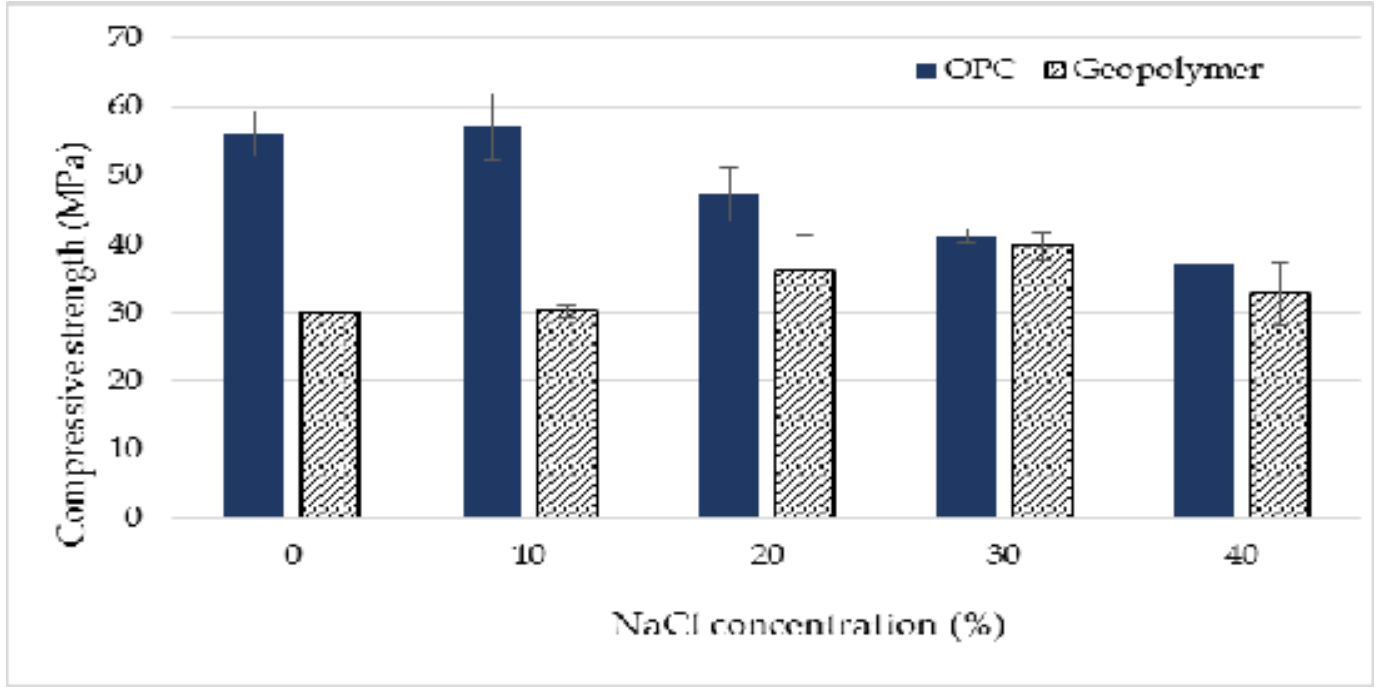

Figure 6 - Comparison of the compressive strength of OPC and geopolymer with salinity level after 45 days of curing 
For a 45 day curing period, Young's modulus of geopolymer increases up to $30 \% \mathrm{NaCl}$ at a rate of $33.5 \%$ and then it decreases towards $40 \%$ $\mathrm{NaCl}$ at a rate of $35 \%$. The initial introduction of $\mathrm{NaCl}$ reduces the failure strain of geopolymer and increases its Young's modulus [3]. Young's modulus of geopolymer decreases at high salinity levels, as the stiffness of geopolymer reduces when the salt content is high. However, the optimum salinity level corresponding to the highest possible Young's modulus in geopolymer is different for 28 and 45 days curing periods $(10 \% \mathrm{NaCl}$ and $30 \% \mathrm{NaCl}$ respectively), and the exact reason for this behaviour is not clear.
Young's modulus of OPC reduces with salinity level for both curing periods. The rates of decrease of the Young's modulus of OPC are $5 \%$ and $11 \%$ for 28 and 45 days curing periods respectively. This means that the stiffness of OPC will decrease as the salinity level is increased by increasing the $\mathrm{NaCl}$ content. However, geopolymer becomes stiffer at higher salinity levels. Furthermore, at any given salinity level the Young's modulus of geopolymer will be generally higher than that of OPC under any curing condition except at low salinity levels (up to $20 \% \mathrm{NaCl}$ ) maintained during 45 days curing. Hence, geopolymer can be used as an alternative to OPC based well-cement in saline mediums because of its higher stiffness.

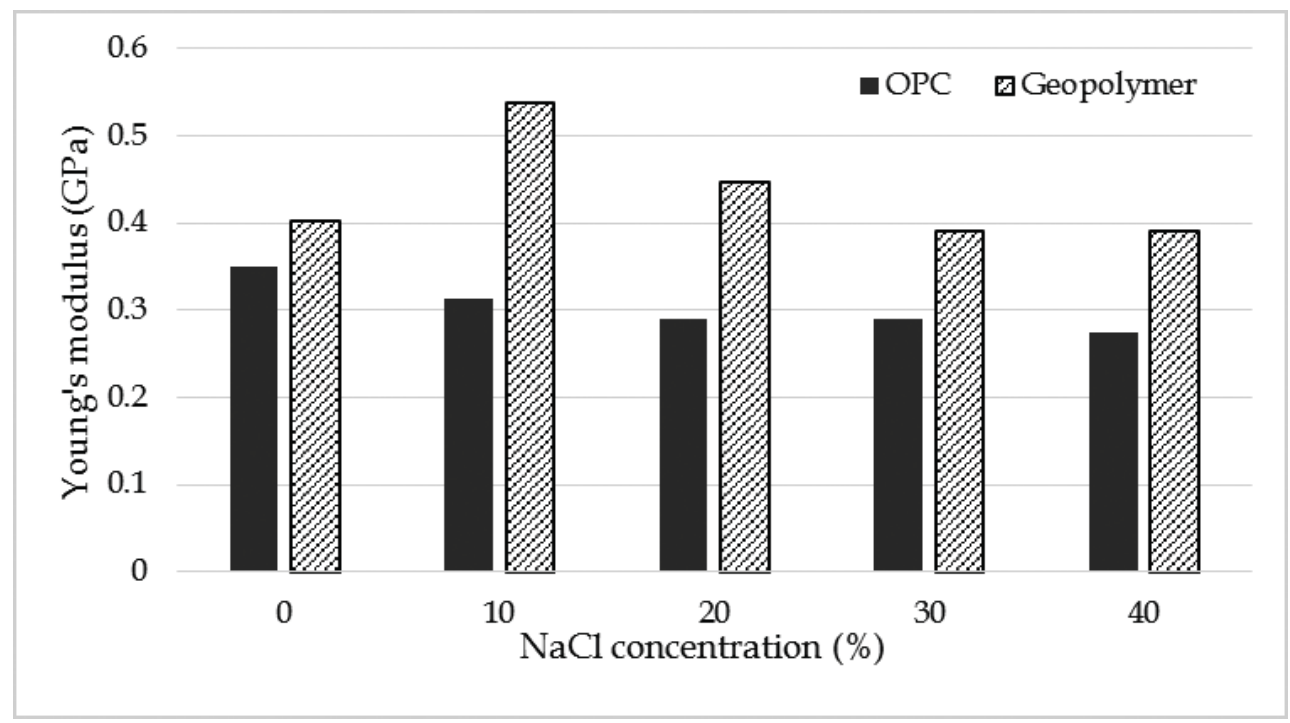

Figure 7 - Comparison of the Young's modulus of OPC and geopolymer with salinity level after 28 days of curing

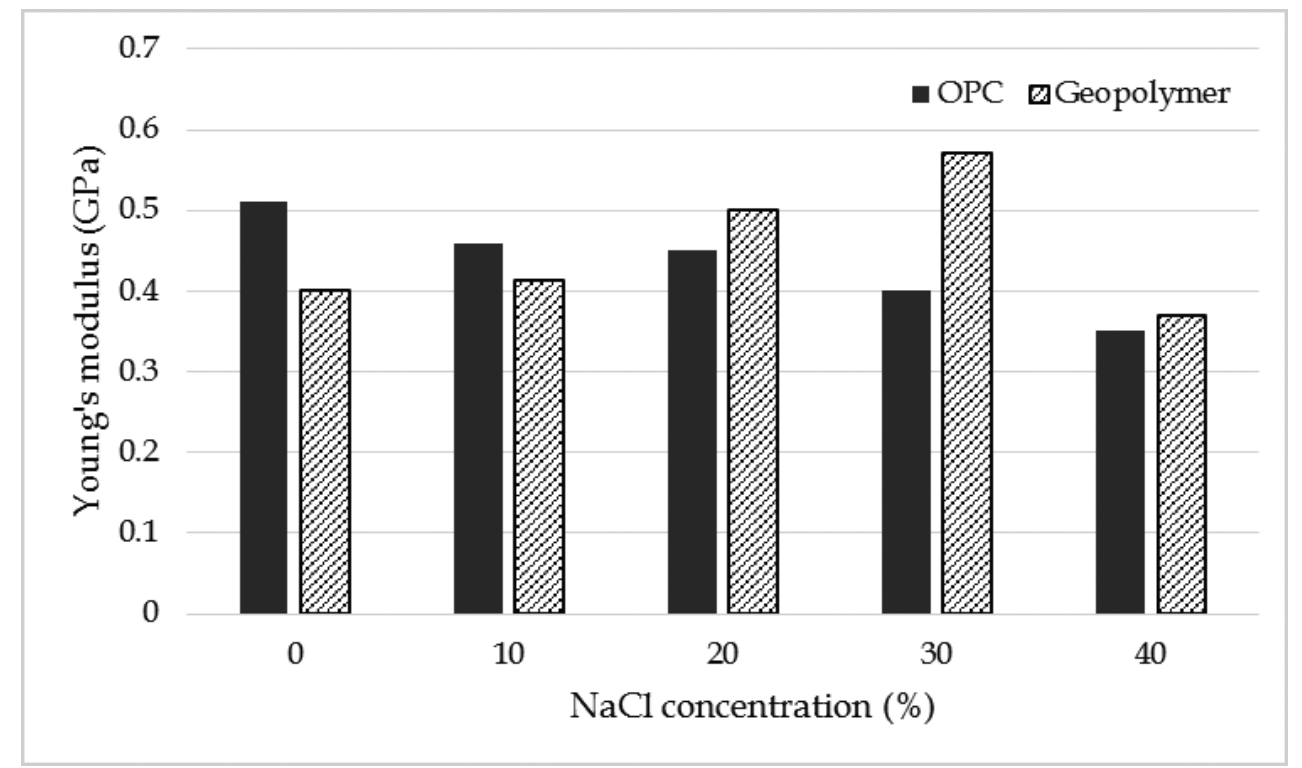

Figure 8 - Comparison of Young's modulus of OPC and geopolymer with salinity level after 45 days of curing 


\subsection{SEM analysis}

Three samples each of OPC and geopolymer cured in brine for 28 days at different salinity levels were selected for the SEM analysis. SEM analysis was used to identify the mechanisms causing the variation of the mechanical behaviours of OPC and geopolymer by identifying the microstructural variations and appearances of the samples cured in different brine solutions. The microstructures of the samples vary because of $\mathrm{NaCl}$ and the hydration process. Figure 9 shows the SEM image of OPC and geopolymer cured for 28 days under different salinity conditions. In Figure 9-1(a), the uniform fibrous surface formed by the hydration process, could be seen in samples cured in plain water $(0 \% \mathrm{NaCl})$. With the introduction of the brine solution, $\mathrm{NaCl}$ micro crystallites get absorbed into the fibrous surface (Figure 9-1(b)). As a result of that the compressive strength of OPC will initially increase. During continuous curing in a brine solution, the $\mathrm{Ca}^{2+}$ ions in Calcium Silica Hydrate (C-S-H) along with $\mathrm{Cl}^{-}$ ions get deposited as $\mathrm{CaCl}_{2}$ crystals in between the cement matrix. It affects the formation of $\mathrm{Ca}(\mathrm{OH})_{2}$. Due to the retardation of hydration as well as the degradation of C-S-H, the strength will reduce with salinity level. It was ensured that the white colour crystals in Figure 9-1 (b and $\mathrm{C}$ ) are $\mathrm{CaCl}_{2}$ solid deposits as it has been found that $\mathrm{CaCl}_{2}$ will get formed when OPC is cured in brine water [11].

From the microstructure of the geopolymer, it can be seen that the particles are packed loosely and that large voids and a fibrous surface (Figure 9-2(d)) are formed when the structure is cured in plain water $(0 \% \mathrm{NaCl})$. With the increase of salinity level, the voids get covered by geopolymeric products and become relatively compact. This scenario could be seen in Figures 9-2(e and f). As it becomes denser with the increase of salinity, geopolymer gains compressive strength.

\section{Conclusions}

An experimental study was conducted to compare the mechanical behaviours of OPC and geopolymer well-cements cured for 7, 28 and 45 days at different salinity levels $(0 \%, 10 \%, 20 \%$, $30 \%$ and $40 \%$ ). A series of Uniaxial Compressive Strength (UCS) tests and the Scanning Electron Microscopy (SEM) test were conducted on the OPC and geopolymer samples.

The compressive strength of OPC initially increases as the salinity level is increased up to $10 \% \mathrm{NaCl}$ due to the rapid increase in the formation of spines which absorb $\mathrm{NaCl}$ micro crystallites and cause the compressive strength to increase with salinity level. The compressive strength begins to decrease as the salinity level is increased beyond $10 \% \mathrm{NaCl}$ since hydration gets retarded due to the high salt content.

On the other hand, the compressive strength of geopolymer will increase with salinity level due to its high resistance against alkali leaching when the salt content is high. Due to loss of stiffness, Young's modulus of OPC samples will get reduced with salinity level.

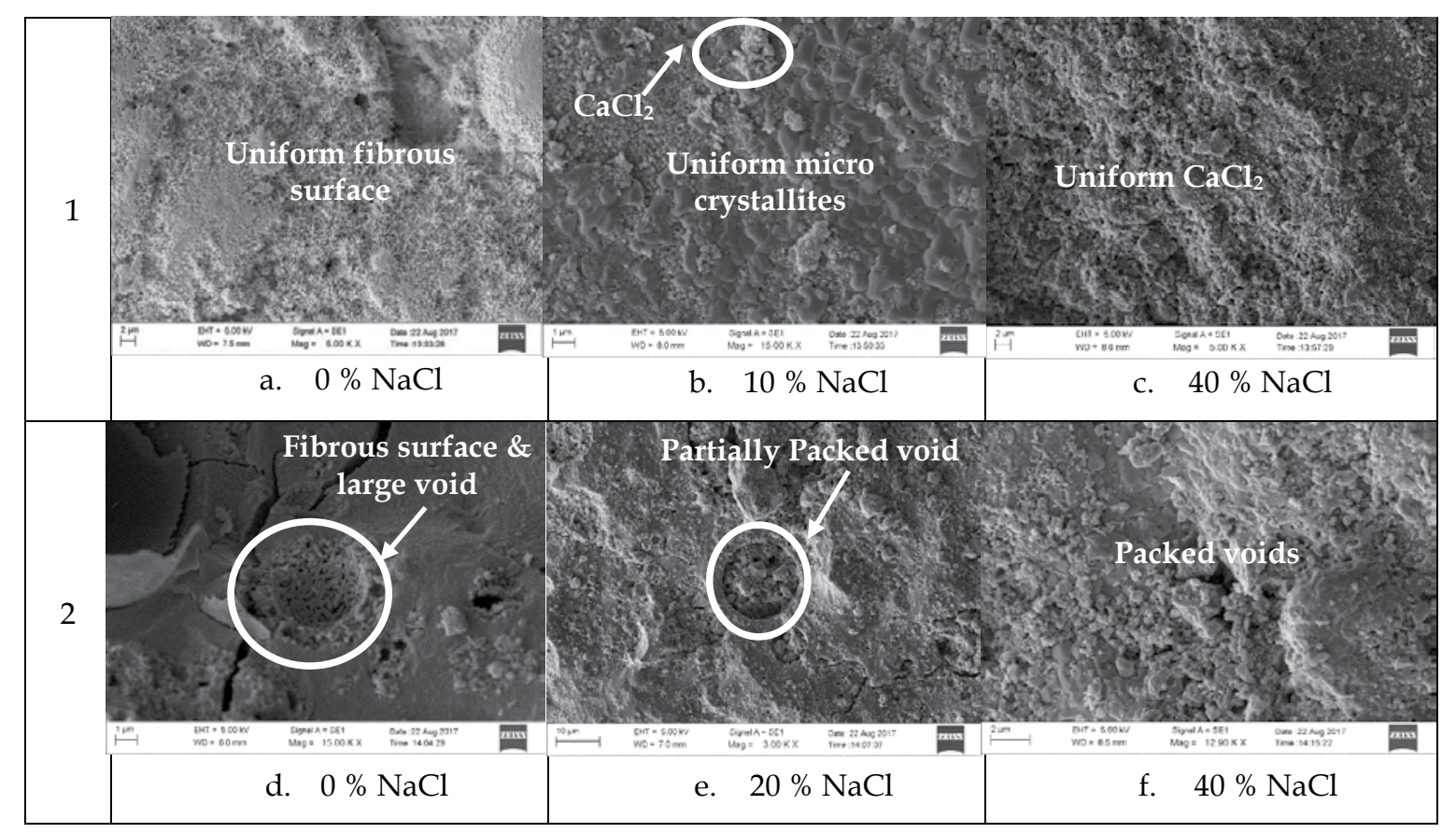

Figure 9 - Variation of microstructure: (1) OPC and (2) Geopolymer 
The introduction of salt will decrease the failure strain in geopolymer and increase its Young's modulus. However, a further increase in the salt content will cause a loss of stiffness and a reduction in the Young's modulus. With continuous aging, OPC gains strength because of the hydration process. However in geopolymer, alkali leaching accelerates with aging, decreasing its compressive strength. To make sure that this behaviour of OPC and geopolymer is due to the presence of $\mathrm{NaCl}$, the results obtained for the compressive strength and Young's modulus were further verified by using the microstructures observed from the SEM.

Although the compressive strength of geopolymer reduces with aging, geopolymer gains more compressive strength than OPC under high salinity levels. In addition, geopolymer becomes stiffer than OPC when exposed to a high salt content. On the whole, it can be concluded that geopolymer performs better than OPC as a well-cement, especially when exposed to higher salinity conditions.

\section{Acknowledgement}

Authors acknowledge the Department of Geology, Faculty of Science, University of Peradeniya, Sri Lanka for the assistance extended to conduct the SEM test for the cement samples.

\section{References}

1. Nasvi, M. C. M., Rathnaweera, T. D., Padmanabhan, E., Geopolymer As Well-Cement and its Mechanical Integrity under Deep DownHole Stress Conditions: Application for Carbon Capture and Storage Wells, Geomechanics and Geophysics for Geo-energy and Geo-Resources, Vol 02, 2016, pp 245-256.

2. Bruant, R., Guswa, A., Celia, M., Peters, C., Safe Storage of $\mathrm{CO}_{2}$ in deep Saline Aquifers. Environmental Science \& Technology, 36, 2002, pp. 240a-245a.

3. Nasvi, M. C. M., Ranjith, P. G., Sanjayan, J., Mechanical Properties of Geopolymer Cement in Brine, $7^{\text {th }}$ Asian Rock Mechanics Symposium, 2012.

4. Bachu, S., Bennion, D. B., Experimental Assessment of brine and/or $\mathrm{CO}_{2}$ Leakage through Well-Cements at Reservoir Conditions, International Journal of Greenhouse Gas Control, 3, 2009, pp. 494-501.
5. Lecolier, E., Rivereau, A., Saout, G. L., Audibert, H. A., Durability of Hardened Portland Cement Paste used for Oil well Cementing, Oil \& Gas Science and Technology Vol. 62 (3), 2007, pp. 335345 .

6. Luke, C., Deasy, H., Lupton, N., Integrity of Wellbore Cement in $\mathrm{CO}_{2}$ Storage Wells State of the Art Review, Australian National Low Emissions Coal Research \& Development Project 3, 2012, pp. 1110-0084.

7. Barlet, V., Rimmele, G., Porcherie, O., Quisel, N., Desroches, J., A Solution Against WellCement Degradation under $\mathrm{CO}_{2}$ Geological Storage Environment, International Journal of Greenhouse Gas Control, 3, 2009,pp. 206- 216.

8. Giasuddin. H. M., Sanjayan. J. G., Ranjith. P. G., Strength of Geopolymer Cured in Saline Water in Ambient Conditions, Fuel, 2013.

9. Kriven, W. M., Bell, J. L., Effect of Alkali Choice on Geopolymer Properties, 28 $8^{\text {th }}$ International Conference on Advance Ceramics and Composites: B, 2004.

10. McNulty, E., Geopolymers: An Environmental Alternative to Carbon Dioxide Producing Ordinary Portland cement, Senior Comprehensive paper, Department of chemistry, The Catolic University of America, 2009.

11. Gowthaman, S., Krishnya, S., Nasvi, M. C. M., Effect of Salinity on Mechanical Behaviour of Well-Cement: Application to Carbon Capture and Storage Wells, ENGINEER- Vol. XLIX, No. 01, 2016, pp. [21-29].

12. Nasvi, M. C. M., Ranjith, P. G., Sanjayan, J., Haque, A., Xiao Li, Mechanical Behaviour of Wellbore Materials Saturated in Brine Water with Different Salinity Levels, Energy 66, 2014, 239 249.

13. Xingshan, Z., Xian, L., Mingjiang, H., Ying, Z., The Hydration of Saline oil Well-Cement, Cement and Concrete Research Vol. 26, 1996, pp. 1753-175.

14. Emilia, L., Christopher, J. S., Colin, J. P., Failure Behaviour Well-Bore Cement in the Presence of Water and Supercritical $\mathrm{CO}_{2}$, Energy Procedia, 2009, pp. 3553-3560. 